\title{
Optimum Choice of Energy System Configuration and Storages for a Proper Match between Energy Conversion and Demands
}

\author{
Andrea Lazzaretto ${ }^{1, *}$ and Andrea Toffolo ${ }^{2}$ \\ 1 Department of Industrial Engineering, University of Padova, via Venezia 1, 35131 Padova, Italy \\ 2 Energy Engineering, Division of Energy Science, Department of Engineering Sciences and Mathematics, \\ Luleå University of Technology, SE-971 87 Luleå, Sweden; andrea.toffolo@ltu.se \\ * Correspondence: andrea.lazzaretto@unipd.it; Tel.: +39-049-8276747
}

Received: 12 September 2019; Accepted: 12 October 2019; Published: 17 October 2019

\begin{abstract}
This Special Issue addresses the general problem of a proper match between the demands of energy users and the units for energy conversion and storage, by means of proper design and operation of the overall energy system configuration. The focus is either on systems including single plants or groups of plants, connected or not to one or more energy distribution networks. In both cases, the optimum design and operation involve decisions about thermodynamic processes, about the type, number, design parameters of components/plants, and storage capacities, and about mutual interconnections and the interconnections with the distribution grids. The problem is very wide, can be tackled with different methodologies and may have several, more or less valuable and complicated solutions. The twelve accepted papers certainly represent a good contribution to perceive its difficulty.
\end{abstract}

Keywords: smart power systems; multi-energy systems; optimization of energy systems design and operation

\section{Introduction}

Energy conversion systems convert a source of energy into the form desired by the users: Electricity, heat, fuel, etc. Users' demands vary with time and can often be predicted only with some uncertainty. On the other hand, the availability of the energy source may also vary depending, e.g., on uncertain weather predictions, as in the case of sun or wind, or on market availability, as in the case of fossil fuels. Thus, a good match between the availability of resources and users' demands is not easy to be found in terms of resource-saving, economic results, or sustainability. This match requires:

(1) A deep preliminary knowledge of the characteristics of the energy sources and the plants that will be included in the overall system, in addition to all the other constraints from the external environment that may limit system utilization (market costs and prices, transportation systems, and others). In this step, the definition of the optimum configuration of each single plant is crucial and involves a proper match among its components according to the purpose of the overall energy system.

(2) The definition of the final system configuration, which requires a proper match between sources, plants, and users. Storage capacities are often necessary to find this match, to store fuels or product energy streams.

The problem of defining a configuration and its design parameters is generally called the "synthesis/design problem" and applies both to single plants and to groups of plants. Plants or groups of plants can work in isolation or can be connected to the electric grid, or to other heat or fuel 
networks. Design and management of plants and networks are two parts of the same problem, i.e., the optimum coupling between users' demand and energy conversion systems, which is the topic of this Special Issue.

\section{Overview of the Papers}

To facilitate the organization of this Special Issue, the papers are subdivided into two main categories, about:

- $\quad$ Optimization of design and operation of groups of energy conversion and storage units;

- $\quad$ Optimization of the design of single energy conversion and storage units.

\subsection{Optimization of Design and Operation of Groups of Energy Conversion and Storage Units}

Sakalis et al. [1] supply very general and detailed information about the mathematical formulation, solution methods, and case studies of intertemporal static and dynamic optimization problems for the synthesis, design, and operation (SDO) of energy systems. The focus is on the energy systems aboard ships. The authors emphasize the imperative need to use optimization methods in this field because of the large variety of possible design configurations and time-changing operating conditions. The examples of application demonstrate that the optimal solution may differ significantly from the solutions suggested by the usual practice. Unlike other works in the literature, where the SDO optimization problems are solved by two- or three-level algorithms, single-level algorithms are applied here tackling all three aspects $(\mathrm{S}, \mathrm{D}, \mathrm{O})$ concurrently. The methods can also be applied on land installations, e.g., power plants, cogeneration systems, etc., with proper modifications.

Wang et al. [2] review existing methodologies for the three general topics of: (1) System evaluation, (2) optimization of the system design, and (3) optimization of the system configuration (synthesis). The focus is on thermal power plants, which are still supposed to play a significant role in the near future. In particular, the authors present the potentialities of advanced exergy-based techniques in the evaluation and design improvement of thermal systems. In the optimization of system design, the focus is on the mathematical formulation, solution algorithms, and design and operating variables that are to be included in the decision variables set. In the optimization of the system configurations, after a general description of typical optimization problems and solving methods, the superstructure-based and -free concepts are reviewed and compared, showing the possible automatic generation of structural alternatives. In each topic, the authors identify the methods with higher possibilities of application and development.

Urbanucci et al. [3] present a methodology for the optimal design and operation of cogeneration systems with thermal energy storage. A two-level algorithm is proposed, which utilizes a genetic algorithm at the design level (upper level) to identify the components that are to be included in the energy system and their capacities, and combines it with a mixed-integer linear programming (MILP) formulation for the search of the optimal operation (lower level). The two problems are nested and solved simultaneously. For each individual solution (components sizes) generated by the upper level, the optimal annual operation cost is identified by the MILP solver, and the total equivalent annual cost is calculated. The procedure is repeated for each individual of each generation generated at the upper level until the stopping criteria are met. A rolling-horizon technique allows dividing the investigated period into smaller periods and optimizing each subproblem in sequence to reduce the computational time required without affecting the quality of the results. The optimized design of a cogeneration system for a secondary school in San Francisco is presented as an example of application. Results show that this system is able to meet around $70 \%$ of both the electric and thermal demands, while the thermal energy storage additionally covers $16 \%$ of the heat demand.

Rech [4] summarizes the basic theoretical and practical concepts that are required to simulate and optimize the design and operation of fleets of energy conversion and storage units, which have to match properly the availability of the resources with users' requirements. The paper is a sort of 
manual, which helps the reader define all steps of the optimization problem. The author supplies instructions to select variables and equations that are required to simulate the dynamic behavior of each conversion and storage unit included in the system, to define the operational constraints and to formulate the objective function (economic profit). A general combined heat and power (CHP) fleet of units is used as an example to present the construction of the dynamic model and the formulation of the optimization problem. The goal is to provide a "recipe" to choose the number and type of energy conversion and storage units that are able to exploit in an optimal way the available sources to fulfill the users' demands.

Vargas-Jaramillo et al. [5] emphasize the importance of properly taking into account the reliability of power networks, which depends on the uncertainties associated with generation, transmission and distribution, load demand, and the presence of unexpected catastrophic events. All these factors affect the sustainability of these networks, making their planning a difficult problem to solve. The authors propose a generation-transmission reliability approach to improve the sustainability assessment of power networks. The approach is based on a quasi-stationary multiobjective optimization problem which takes into account, at every node and instant of time, the propagation of uncertainties along the transmission lines, the uncertainties of the generation system (including the fluctuating effects associated with the wind and photovoltaic energy producers), and the uncertainties of the load demand. Six different objective functions are considered: The total daily costs for the economic aspects, $\mathrm{SO} 2$ and $\mathrm{CO} 2$ daily emissions for the environmental aspects, the disability-adjusted life year (DALY) for the social aspects, and the exergetic efficiency and expected energy not supplied (EENS) for the technical aspects. The sustainability-reliability approach is applied to the standard IEEE reliability test system [6] composed of several generation units and transmission lines, as well as nodes where only generation capacity or load demand are present. Results show that using a mixture of normals approximation (MONA) for the formulation of the EENS makes the reliability analysis simpler, and possible in large-scale optimization problems. Moreover, the authors emphasize the positive impact, in terms of sustainability, of including renewable energy producers in the optimal synthesis/design of power networks, counterbalanced by the negative impact on reliability.

Tran and Smith [7] propose a stochastic approach to minimize the operating cost of a district energy system (DES), including a CHP system, natural gas boilers, solar photovoltaics (PV), and wind turbines for generation of power, heating, and cooling. A district of buildings on a university campus is used as a case study. A Monte Carlo study is performed to analyze the stochastic power generation from the renewable energy resources in the DES. The optimization of the DES is carried out with a particle swarm optimization (PSO) algorithm in each hour of a day, to bid in the day-ahead market. The results suggest that the proposed DES can achieve approximately a 10\% operating cost reduction with respect to the current system. The focus is on the importance of considering the uncertainty of energy loads and power generation from renewable energy sources to properly evaluate the operating costs of the DES, and in turn, plan correct management of the energy generation.

Mikolajková-Alifov et al. [8] tackle the problem of optimizing the supply chain of liquefied natural gas (LNG), compressed natural gas (CNG), or biogas for smaller regions. The task is to find the best supplier and the most efficient way to transport the gas to the customers to cover their demands, including the design of pipeline networks, truck transportation, and storage systems. To fulfil this task, the authors develop a mathematical model of a gas supply chain where gas may be supplied by pipeline, as compressed gas in containers or as LNG by tank trucks, with the goal to find the solution that corresponds to lowest overall costs. A mixed-integer linear programming approach is used to reduce the computational time. The model is applied to a gas distribution problem in western Finland and considers constraints and costs of the delivery and the investments required to realize the system. Therefore, it can be used to analyze the sensitivity of the design of the supply chain to changes in the parameters (e.g., constraints or costs) or in the gas supply and demand. Results show that the fuel price has a major effect on the optimal supply chain, including which fuel sources are to be used and how to deliver the gas to the customers. The costs of storage and pipes mainly influence the length 
of the pipeline and the number of storages to be constructed. Although the model is presented for a single-period problem (i.e., with fixed demands) it can be extended to multi-period problems. This will, however, increase the complexity of the numerical problem, restricting the size of the problems that can be solved without prohibitive computational burden.

Harahap et al. [9] look into the supply chain optimization of palm oil biomass residues in Sumatra island (Indonesia). A biomass supply chain includes biomass harvesting and collection, pretreatment, storage, transport and conversion into bio-based products, so its optimization heavily relies on the selection of plants, units, components, and technologies forming the configuration of the supply chain (also with reference to its spatial layout). In the paper, the optimization is performed using the BeWhere model. BeWhere is a geographically explicit techno-economic model, developed at the International Institute for Applied Systems Analysis (IIASA), which adopts a mixed-integer linear representation translated into GAMS equations and solved by CPLEX. The results from the maximization of supply chain profits show that palm oil biomass residues can be conveniently transformed into both energy and non-energy products, contributing to sustainable growth of the palm oil industry.

\subsection{Optimization of the Design of Single Energy Conversion and Storage Units}

Seki and Amano [10] propose a bottom-up procedure to build absorption systems configurations by a combination of elementary processes. The procedure brings ideas from the SYNTHSEP methodology [11-15] to form the so-called "basic configuration" of a system as a set of elementary thermodynamic cycles or part of them $[16,17]$, using an original approach for the implementation. The authors present two examples of application under simplified/idealized operating conditions to show that existing absorption systems, otherwise designed on the basis of experience, could be obtained automatically. The final aim of the methodology is to allow engineers predicting all possible configurations of absorption systems and identifying simple yet feasible optimal ones.

Fiaschi et al. [18] propose a solar-integrated thermo-electric energy storage (TEES) system for one to two daily hours of operation to compensate for the mismatch between electricity generation and demand in small-to-medium-size photovoltaic systems (4 to $50 \mathrm{kWe}$ ). Given the drawbacks of alternative storage systems in this range of power, such as the limited life cycle of batteries or the low round-trip efficiency of chemical storage, the authors believe that TEES systems may represent an interesting solution to guarantee dispatchability to energy systems based on renewables. The proposed system consists of a power cycle, a solar-assisted heat pump, and a solar-assisted refrigeration cycle matched with properly sized hot and cold reservoirs of warm water at $120 / 160{ }^{\circ} \mathrm{C}$ and ethylene glycol at $-10 /-20^{\circ} \mathrm{C}$. In the storage mode, a supercritical heat pump restores sensible heat to the hot reservoir, while a cooling cycle cools the cold reservoir. Both the heat pump and cooling cycle operate on photovoltaic (PV) energy, and benefit from solar heat integration at low-medium temperatures $\left(80-120^{\circ} \mathrm{C}\right)$. The power cycle is a trans-critical CO2 unit, including recuperation. The thermodynamic cycles are designed and optimized from an exergy and exergo-economic perspective to search for the highest possible performance for a variable heat input depending on the availability of the solar resource. Results show that the system can deliver electric energy with a marginal round-trip efficiency of around $50 \%$ without considering the solar heat input to solar-thermal collectors. The exergy round-trip efficiency is of the order of $35 \%$. The levelized cost of electricity is around $0.7-0.75 € / \mathrm{kWh}$, in line or slightly better than documented stand-alone renewable configurations. The authors observe that this cost is still pretty high because of the high costs of the solar collectors and of the refrigeration cycle, but it could be significantly improved working both on the reduction of equipment cost and on optimized control strategies.

Guewouo, et al. [19] optimize the design of a small-scale compressed-air energy storage (CAES) system operating without fossil fuel. To do that, they build a model of the system and use a modified real coded genetic algorithm (RCGA) to find the values of thirteen selected design parameters that maximize the global exergy efficiency. The model is partially validated (i.e., only for the filling and the discharge of the tank) with data from an experimental prototype existing in the authors' lab. The results 
of the optimization indicate that the electric energy consumed by the compressor is $103.83 \mathrm{kWh}$ and the electric energy output is $25.82 \mathrm{kWh}$ for the system charging and discharging times of about 8.7 and $2 \mathrm{~h}$, respectively. This corresponds to an optimal round-trip efficiency of $79.07 \%$ and to a global exergy efficiency of $24.87 \%$. The analysis of the variation of all design parameters during the evolution of the optimization process allows the authors to evaluate the effect of each design parameter on the global exergy efficiency. In particular, results show that a low mass flow of the pneumatic air motor coupled with a high mass flow rate of the compressor improves the efficiency of the storage system and the maximum value of air storage tank volume allowed by the constraints of space, cost, charge and discharge time should be preferred.

Margheritini and Kofoed [20] investigate the feasibility of a wave energy system made up of a number of Weptos wave energy converters (WECs) and sets of batteries, to provide the energy demands of a small island in Denmark. They simulate over one year the behavior of the combination of two different configurations of these machines, for a total installed power of $750 \mathrm{KW}$, supplemented by a 3 MWh battery bank and a backup generator. The goal consists in demonstrating that they are able to provide the total energy needs of the island. Due to the imbalance between demand and production, this goal is achieved only with the intervention of the backup generator, which covers approximately $5 \%$ to $7 \%$ of consumption, even if Weptos WECs supply much more energy than requested.

\section{Conclusions}

The twelve papers of this Special Issue show different approaches and applications to the synthesis of new configurations of energy systems made up of groups of plants and storage capacities, or single plants with or without storage capacities. All papers emphasize the criticalities involved in the search for the best match between production and demands, addressing both methodological and application aspects. Although far from being exhaustive, the presented overview is able to show the main problems and solutions in the search for new configurations of energy systems interconnected or not with the energy distribution grids.

Conflicts of Interest: The authors declare no conflict of interest.

\section{References}

1. Sakalis, G.N.; Tzortzis, G.J.; Frangopoulos, C.A. Intertemporal Static and Dynamic Optimization of Synthesis, Design, and Operation of Integrated Energy Systems of Ships. Energies 2019, 12, 893. [CrossRef]

2. Wang, L.; Yang, Z.; Sharma, S.; Mian, A.; Lin, T.E.; Tsatsaronis, G.; Maréchal, F.; Yang, Y. A Review of Evaluation, Optimization and Synthesis of Energy Systems: Methodology and Application to Thermal Power Plants. Energies 2019, 12, 73. [CrossRef]

3. Urbanucci, L.; D'Ettorre, F.; Testi, D. A Comprehensive Methodology for the Integrated Optimal Sizing and Operation of Cogeneration Systems with Thermal Energy Storage. Energies 2019, 12, 875. [CrossRef]

4. Rech, S. Smart Energy Systems: Guidelines for Modelling and Optimizing a Fleet of Units of Different Configurations. Energies 2019, 12, 1320. [CrossRef]

5. Vargas-Jaramillo, J.R.; Montanez-Barrera, J.A.; von Spakovsky, M.R.; Mili, L.; Cano-Andrade, S. Effects of Producer and Transmission Reliability on the Sustainability Assessment of Power System Networks. Energies 2019, 12, 546. [CrossRef]

6. Billinton, R.; Kumar, S.; Chowdhury, N.; Chu, K.; Debnath, K.; Goel, L.; Khan, E.; Kos, P.; Nourbakhsh, G.; Oteng-Adjei, J. A Reliability Test System for Educational Purposes. IEEE Trans. Power Syst. 1989, 4, 1238-1244. [CrossRef]

7. Tran, T.T.D.; Smith, A.D. Stochastic Optimization for Integration of Renewable Energy Technologies in District Energy Systems for Cost-Effective Use. Energies 2019, 12, 533. [CrossRef]

8. Mikolajková-Alifov, M.; Pettersson, F.; Björklund-Sänkiaho, M.; Saxén, H. A Model of Optimal Gas Supply to a Set of Distributed Consumers. Energies 2019, 12, 351. [CrossRef]

9. Harahap, F.; Leduc, S.; Mesfun, S.; Khatiwada, D.; Kraxner, F.; Silveira, S. Opportunities to Optimize the Palm Oil Supply Chain in Sumatra, Indonesia. Energies 2019, 12, 420. [CrossRef] 
10. Seki, K.; Takeshita, K.; Amano, Y. Development of Complex Energy Systems with Absorption Technology by Combining Elementary Processes. Energies 2019, 12, 495. [CrossRef]

11. Toffolo, A. A synthesis/design optimization algorithm for Rankine cycle based energy systems. Energy 2014, 66, 115-127. [CrossRef]

12. Toffolo, A.; Rech, S.; Lazzaretto, A. Generation of complex energy systems by combination of elementary processes. J. Energy Resour. Technol. 2018, 140, 112005. [CrossRef]

13. Lazzaretto, A.; Manente, G.; Toffolo, A. SYNTHSEP: A general methodology for the synthesis of energy system configurations beyond superstructures. Energy 2018, 147, 924-949. [CrossRef]

14. Toffolo, A.; Lazzaretto, A. A Practical Tool to Generate Complex Energy System Configuration Based on the SYNTHSEP Methodology. Int. J. Thermodyn. 2019, 22, 45-53.

15. Toffolo, A.; Lazzaretto, A. Building the basic configuration of compression refrigeration systems with the SYNTHSEP method. In Proceedings of the ECOS 2019-The 32nd International Conference on Efficiency, Cost, Optimization, Simulation and Environmental Impact of Energy Systems, Wroclaw, Poland, 23-28 June 2019.

16. Lazzaretto, A.; Toffolo, A. A method to separate the problem of heat transfer interactions in the synthesis of thermal systems. Energy 2008, 33, 163-170. [CrossRef]

17. Morandin, M.; Toffolo, A.; Lazzaretto, A. Superimposition of Elementary Thermodynamic Cycles and Separation of the Heat Transfer Section in Energy Systems Analysis. J. Energy Resour. Technol. 2013, 135, 021602. [CrossRef]

18. Fiaschi, D.; Manfrida, G.; Petela, K.; Talluri, L. Thermo-Electric Energy Storage with Solar Heat Integration: Exergy and Exergo-Economic Analysis. Energies 2019, 12, 648. [CrossRef]

19. Guewouo, T.; Luo, L.; Tarlet, D.; Tazerout, M. Identification of Optimal Parameters for a Small-Scale Compressed-Air Energy Storage System Using Real Coded Genetic Algorithm. Energies 2019, 12, 377. [CrossRef]

20. Margheritini, L.; Kofoed, J.P. Weptos Wave Energy Converters to Cover the Energy Needs of a Small Island. Energies 2019, 12, 423. [CrossRef]

(C) 2019 by the authors. Licensee MDPI, Basel, Switzerland. This article is an open access article distributed under the terms and conditions of the Creative Commons Attribution (CC BY) license (http://creativecommons.org/licenses/by/4.0/). 